\title{
An innovative nonpharmacological intervention combined with intravenous patient-controlled analgesia increased patient global improvement in pain and satisfaction after major surgery
}

\author{
This article was published in the following Dove Press journal: \\ Neuropsychiatric Disease and Treatment \\ 6 April 2017 \\ Number of times this article has been viewed
}

\section{Chia-Chun Chuang' \\ Chien-Ching Lee ${ }^{1,2}$ \\ Li-Kai Wang' \\ Bor-Shyh Lin² \\ Wen-Ju Wu' \\ Chung-Han $\mathrm{Ho}^{3}$ \\ Jen-Yin Chen ${ }^{1,4}$}

'Department of Anesthesiology, Chi Mei Medical Center, ${ }^{2}$ Department of Imaging and Biomedical

Photonics, National Chiao Tung University, ${ }^{3}$ Department of Medical Research, Chi Mei Medical Center, ${ }^{4}$ Department of the Senior Citizen Service Management, Chia Nan University of Pharmacy and Science, Tainan, Taiwan, Republic of China

Correspondence: Jen-Yin Chen Department of Anesthesiology, Chi Mei Medical Center,

No 901, Zhonghua Road, Yongkang,

Tainan 710, Taiwan, Republic of China

Tel +886628 I 28II 53322

Fax +88662832639

Email chenjenyin@gmail.com
Purpose: This study aimed to evaluate whether a nonpharmacological approach through implementation of a communication improvement program (named CICARE for Connect, Introduce, Communicate, Ask, Respond and Exit) into standard operating procedure (SOP) in acute pain service (APS) improved satisfaction in patients receiving intravenous patientcontrolled analgesia (IV-PCA).

Patients and methods: This was a nonrandomized before-after study. Adult patients (aged between 20 and 80 years) who received IV-PCA after major surgery were included. Implementing CICARE into SOP was conducted in APS. Anonymous questionnaires were used to measure outcomes in this prospective two-part survey. The first part completed by APS nurses contained patients' characteristics, morphine dosage, delivery/demand ratios, IV-PCA side effects and pain at rest measured with an 11-point numeric rating scale (NRS, 0-10). A score of NRS $\geq 4$ was defined as inadequately treated pain. The ten-question second part was completed by patients voluntarily after IV-PCA was discontinued. Each question was assessed with a 5-point Likert scale (1: extremely poor; 5: excellent). Patients were separated into "before" and "after" CICARE groups. Primary outcomes were patient global impression of improvement in pain (PGI-Improvement) and patient satisfaction. Secondary outcomes included quality of communication skills, instrument proficiency and accessibility/availability of IV-PCA.

Results: The response rate was $55.3 \%$, with 187 usable questionnaires. CICARE effectively improved patient global impression of improvement in pain, patient satisfaction, communication skills and accessibility/availability of IV-PCA. No significant differences were noted in instrument proficiency, morphine dosage, delivery/demand ratios, rates of inadequately treated pain at rest and side effects of IV-PCA between groups. Paradoxical findings were noted between the rates of inadequately treated pain/side effects and PGI-Improvement in pain/patient satisfaction, which were affected by psychological factors.

Conclusion: Nonpharmacological interventions carried out by implementing CICARE into SOP for APS effectively improved patient satisfaction and postoperative pain management quality, but this did not affect actual pain.

Keywords: acute pain service, patient-physician communication, nonpharmacological approach, patient-controlled analgesia, patient satisfaction

\section{Introduction}

Postoperative acute pain is an important issue. Poor management of postoperative acute pain may lead to severe complications such as pneumonia, deep vein thrombosis and 
chronic pain. IV-PCA has been widely used for postoperative pain management. Improvement of both pain management efficacy and care quality is essential for achieving better outcomes in postoperative IV-PCA patients. ${ }^{1,2}$ Proposed methods include pharmacological and nonpharmacological approaches, such as effective formulas, to lower pain intensity, the reduction of side effects, an easier PCA mechanical design and reaching patients' perceptions of support. ${ }^{3-6}$ PCA is often provided by an APS team, which is composed of anesthesiologists and nurses with specialized training in pain management. ${ }^{7,8}$ The amount of time anesthesiologists spend conferring with patients is usually limited compared to that by other physicians because of job attributes. From a patient's perspective, time spent with physicians is associated with the patient-physician relationship, ${ }^{9}$ which effective communication greatly affects. ${ }^{10,11}$ Therefore, it is important for anesthesiologists to improve pain management efficacy and care quality by establishing effective communication regardless of time constraints. More importantly, communication skills are learnable, improvable and measurable. ${ }^{12}$

CICARE is a quality improvement program developed by the UCLA Medical Center to improve communication skills and patient care. ${ }^{13}$ Moreover, Stanford Health Care's CICARE also supports the validity and the reliability of this nonpharmacological intervention in clinical practice. ${ }^{14}$ It targets six communication behaviors, which are as follows: Connect (make eye contact and connect with patients and family members by addressing them appropriately), Introduce (introduce yourself properly), Communicate (pertinent information), Ask (patient's needs and condition), Respond (prompt response) and Exit (exit courteously after explanation). ${ }^{15}$ A team approach may help manage the physician's time more effectively and enhance the patient-physician relationship positively. ${ }^{16,17}$ In addition, the standardization of medical procedures is central to any improvement of patient care. ${ }^{17}$ Accordingly, a nonpharmacological intervention through CICARE training and SOP for ward visits was expected to improve the efficacy and quality of pain management for the APS team.

Patient satisfaction is a patient-reported outcome that has been shown to be an index of health care quality and effective communication. ${ }^{2,18}$ Patient questionnaires are useful for measuring the behavioral skills of team members and the quality of patient care. ${ }^{19,20}$ Therefore, a questionnaire survey in groups "before" and "after" CICARE was conducted anonymously to investigate whether implementing CICARE through SOP for the APS team improved communication skills, PGI-Improvement in pain and patient satisfaction in patients receiving postoperative IV-PCA. ${ }^{17,21}$
Moreover, morphine dosage, delivery/demand ratio, pain severity and the rates of side effects of IV-PCA after surgery were compared between the groups.

\section{Patients and methods}

The prospective study was approved by the IRB of Chi Mei Medical Center, a 1,200-bed hospital that provides primary, outpatient and specialty care services to the local population of Tainan, Taiwan (IRB approval number: 09904-009) and was registered in a publicly accessible database (Trial ID: UMIN000016342).

\section{APS team and pain assessment}

At the Chi Mei Medical Center, a nurse-based, anesthesiologistsupervised team offers APS, which is available 24 hours a day and 7 days a week. APS team members visited the IV-PCA patients twice a day regularly. The initial visit was provided by an anesthesiologist and a pain nurse, whereas the follow-up visits were usually performed by pain nurses. A standard IV-PCA formula of morphine was used to ensure the uniformity of the PCA service. PCA machines were routinely set to deliver a bolus dose without continuous infusion. ${ }^{22}$ Pain severity was measured on an 11-point verbal NRS, with 0 indicating no pain and 10 representing the worst pain imaginable. ${ }^{21}$ A score of NRS $\geq 4$, defined as inadequately treated pain, was promptly treated by dosage adjustments. ${ }^{23}$ For each patient, the effectiveness of analgesia and the side effects were assessed and recorded during every visit. If there were any problems related to IV-PCA, an anesthesiologist responded immediately and performed an extra visit 2-4 hours later. ${ }^{22}$

\section{Patient population}

Adult patients (aged between 20 and 80 years) who received IV morphine via a PCA device for at least 2 days were included. Currently, PCA use lasts no more than 3-4 days. ${ }^{3}$ Exclusion criteria included ICU patients and those who were blind, deaf or sedated. Based on chart reviews and/or statements of patients and patients' families, patients suffering from preoperative cognitive impairment and/or dementia, as well as patients with daily use of opioid analgesics and nonopioid medications (eg, gabapentinoids and tricyclic antidepressants) $\geq 30$ days before their operation, were excluded. Moreover, patients with anesthetic/surgical complications were excluded. . $^{3,22}$

\section{Instrument and intervention}

Using survey questionnaires, the care quality of acute pain management in postoperative patients receiving IV-PCA 
Table I Visitation schedule and assessment of questionnaires

\begin{tabular}{llll}
\hline $\begin{array}{l}\text { Questionnaire } \\
\text { contents }\end{array}$ & Screening & $\begin{array}{l}\text { Daily } \\
\text { ward } \\
\text { visits }\end{array}$ & $\begin{array}{l}\text { After } \\
\text { termination } \\
\text { of IV-PCA }\end{array}$ \\
\hline Part I: recorded by pain nurses & & - & - \\
\hline Patients' characteristics & - & - & - \\
$\begin{array}{l}\text { Pain severity and total } \\
\text { daily dosage of morphine }\end{array}$ & - & & \\
$\begin{array}{l}\text { Side effects of IV-PCA } \\
\text { Part 2: a I0-item questionnaire }\end{array}$ & - & - & - \\
completed by patients voluntarily & & - & - \\
\hline
\end{tabular}

Note: The dot indicates the action that should be conducted.

Abbreviation: IV-PCA, intravenous patient-controlled analgesia.

was investigated. An anonymous two-part questionnaire was used in this study (Table 1). ${ }^{24}$ The first part was assessed and recorded by APS pain nurses. It contained patients' characteristics, pain severity at rest and side effects of IV-PCA in the "first" and "second" 24 hours after surgery. The second part was completed by patients voluntarily after the termination of IV-PCA usage. PSQs have been identified as a validated tool for assessing the care quality from the patient's perspective. ${ }^{25}$ Based on the five dimensions of PSQ-18, this questionnaire was designed and simplified to ten questions ${ }^{26}$ (Table 2). Each question (Q) was assessed using the 5-point Likert scale, with 1 indicating extremely poor and 5 indicating excellent. Q1 and Q2 were related to the dimension of "accessibility and convenience", as accessibility and availability of PCA information and device; Q3 and Q4 asked about the dimension of "communication", as quality of communication skills; Q5-Q7 investigated the dimension of "interpersonal manner", as the attitude of managing patient's problem; Q8 dealt with the dimension of “technical quality”, as instrument proficiency; Q9 and Q10 were related to the dimension of "general satisfaction", as PGI-Improvement in pain and patient overall satisfaction with APS. The content validity of this questionnaire was confirmed by five experts in pain management at the Chi Mei Medical Center with I-CVI of $0.85 .{ }^{27}$ The reliability of this questionnaire was confirmed by the Cronbach's alpha value of 0.947 in the pretest 50 questionnaires.
CICARE has been implemented throughout Chi Mei Medical Center since September 2013. ${ }^{15}$ Accordingly, members of the APS team received CICARE training in September 2013. The SOP of CICARE for APS team members during ward visits was established. An additional file shows this in more detail (Supplementary material). The importance of CICARE is regularly reinforced during monthly APS staff meetings. ${ }^{28}$

This study was a single-blind study. The APS team members had deep understanding of skills needed for performing CICARE during visits to patients, while patients did not know about CICARE strategy. For assessing the efficacy of CICARE, patients who received major surgery under general anesthesia were separated into two groups: "before" and "after" CICARE. Patients' data in September 2013 were excluded because the APS team was trained for "CICARE" during this period. The before time frame was from April 1, 2013, to August 31, 2013, and the after time frame was from October 1, 2013, to February 28, 2014 (study design flowchart is shown in Figure 1).

\section{Ethical approval}

A communication skill program can give rise to misunderstanding questions, and behavior or communication patterns included in the program may affect the patients, leading to psychiatric disorders such as depression or anxiety, if not done properly by one of the team or the patient. In particular, patients suffering from personality disorders may be highly affected by any type of communication behavior. ${ }^{29}$ In this research, the CICARE program of a regular service was applied to IV-PCA patients after major surgery (Table S1). We consulted psychiatrists to help understand the morality of patients when any behavior or communication problems occurred postoperatively. ${ }^{22}$ The CICARE strategy applied by UCLA Medical Center and Stanford Medical Center has been shown to achieve excellence and improvement in both medical quality and patient satisfaction. Hence, the research presented no risk to the subjects. ${ }^{13-15}$ The questionnaire was anonymous. Thus, the

Table 2 Dimensions of the survey questionnaire used to evaluate the care quality of acute pain services

\begin{tabular}{ll}
\hline Dimensions & Question and assessment \\
\hline Accessibility and & Accessibility: QI - PCA information \\
convenience & Availability: Q2 - PCA device and pain treatment \\
Communication & Communication skills: Q3 - initial explanation on the use of PCA; Q4 - follow-up questions during ward visits \\
Interpersonal manner & Ask-and-response: Q5 - for ward nurses; Q6 and Q7 - for acute pain service team members \\
Technical quality & Instrument proficiency: Q8 - operating the PCA device \\
General satisfaction & Global improvement: Q9 - patient global impression of improvement in pain \\
& Overall satisfaction: Q $10-$ patient overall satisfaction with acute pain services \\
\hline
\end{tabular}

Abbreviations: Q, question; PCA, patient-controlled analgesia. 


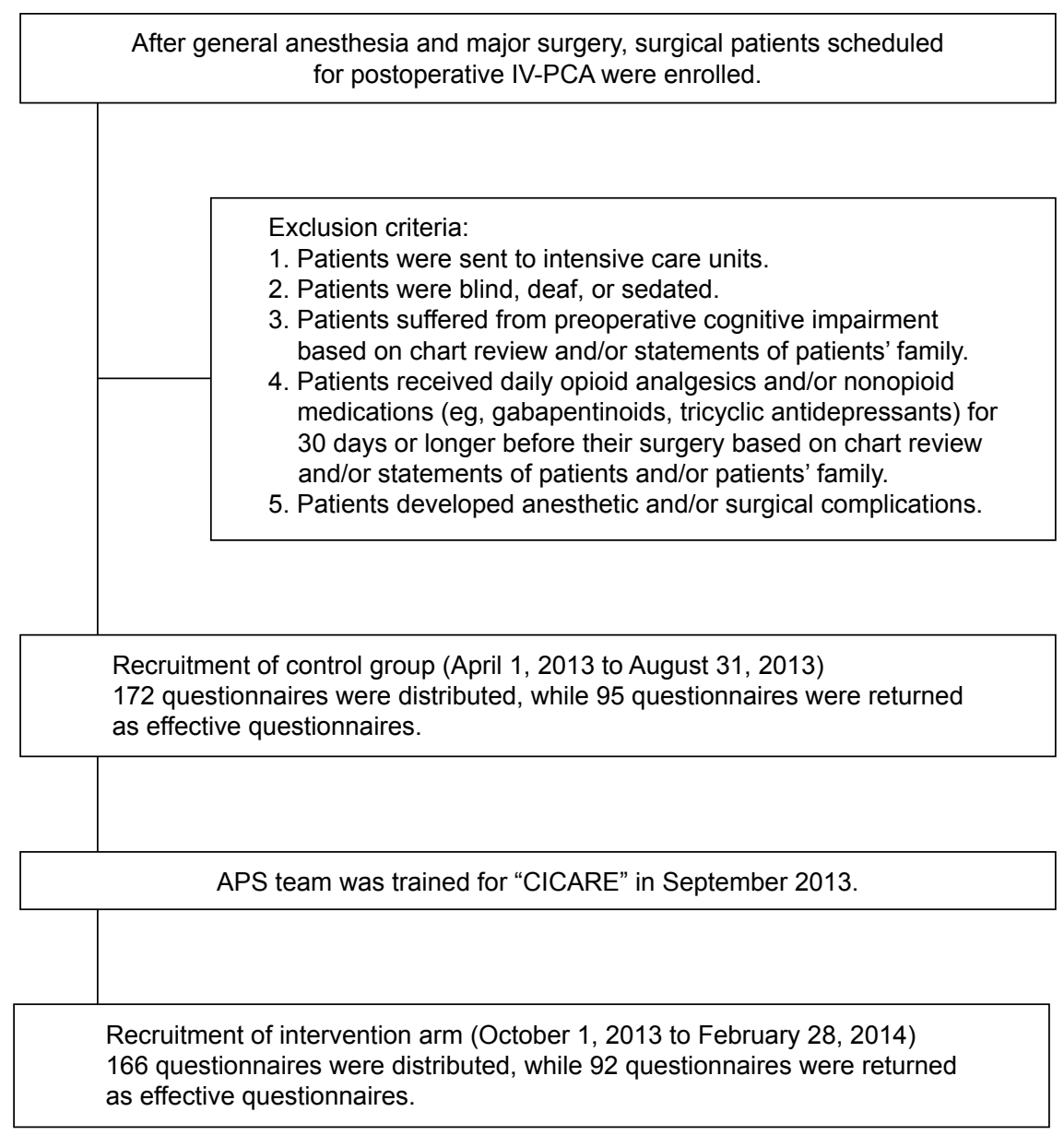

Figure I Flowchart of study design.

Abbreviations: APS, acute pain service; CICARE, Connect, Introduce, Communicate, Ask, Respond and Exit program; IV-PCA, intravenous patient-controlled analgesia.

IRB of Chi Mei Medical Center approved this study and also approved the use of an oral consent procedure rather than a written consent form for the collection and use of the medical information for all subjects. ${ }^{13}$

\section{Outcome measures}

Primary outcomes were PGI-Improvement in pain and patient overall satisfaction with APS. ${ }^{21}$ Secondary outcomes included accessibility and availability of PCA information and device, quality of communication skills and instrument proficiency. Additional assessments included the morphine dosage, delivery/demand ratios, severity of pain at rest and the rates of side effects of IV-PCA, including itching, dizziness and nausea/vomiting in the "first" and "second" 24 hours after surgery.

\section{Sample size}

Based on the previous study, using a 5-point Likert scale on questions, the differences in patient satisfaction with the service team and the instrument proficiency in the before and after intervention groups were estimated. A minimum sample size of patients (43 in each group) was determined to ensure high power (power $=0.8$ ), with a $5 \%$ level of statistical significance for an analysis of the questions. ${ }^{30}$

\section{Statistics}

Data were analyzed using STATA 12.0 (StataCorp, College station, TX, USA) statistical software. Categorical characteristics of postoperative patients between survey groups were measured by the chi-square test and continuous variables were measured by the Student's $t$-test. The results from the ten questions measured by a 5 -point Likert scale were treated as ordinal data and analyzed by Student's $t$-test. ${ }^{31}$ Based on previous research, the minimal clinically important difference for the change of patient-reported outcomes on a 5-point Likert scale is defined as $>0.3 .{ }^{32}$ Morphine dosage and delivery/demand ratios between survey groups were compared by Student's $t$-test. Pain severity and rates of side effects in patients between 
survey groups were measured by the chi-square test. A $P$-value of $<0.05$ was considered significant.

\section{Results}

In total, 338 questionnaires were distributed, while 187 questionnaires were returned as effective questionnaires, resulting in a total effective response rate of $55.3 \%$. There were no significant differences in the characteristics of postoperative patients using IV-PCA after major surgery between the groups (Table 3).

\section{Primary and secondary outcomes}

PGI-Improvement in pain and patient satisfaction in the "after CICARE" group were rated with mean values of 4.4 (SD: 0.6 ) and 4.3 (SD: 0.6), respectively, which were significantly greater than those (mean: 4.0, SD: 0.6; mean: 3.8 , SD: 0.5 , respectively) in the "before CICARE" group $(P<0.001$ and $P<0.001$, respectively; mean change difference $=0.4$ and 0.5 , respectively). Clearly, the implementation of CICARE through SOP significantly improved PGI-Improvement in pain and patient satisfaction with the APS team. The findings demonstrate that effective communication, which is emphasized through SOP, is important for medical care and patient satisfaction. In the dimension regarding accessibility and availability of PCA information and device (Q1-Q2),

Table 3 Characteristics of postoperative patients receiving patientcontrolled analgesia between the two survey groups, namely, "before" and "after" CICARE

\begin{tabular}{|c|c|c|c|}
\hline \multirow[t]{2}{*}{ Characteristics } & $\begin{array}{l}\text { Before } \\
\text { CICARE }\end{array}$ & $\begin{array}{l}\text { After } \\
\text { CICARE }\end{array}$ & \multirow[t]{2}{*}{ P-value } \\
\hline & $n=95$ & $\mathrm{n}=92$ & \\
\hline \multicolumn{2}{|c|}{ Questionnaire response rate $55.2 \%(95 / 172)$} & $55.4 \%(92 / 166)$ & 0.97 \\
\hline \multicolumn{2}{|c|}{ Age group, years, number (\%) } & & 0.14 \\
\hline $20-39$ & $16(16.8)$ & II (I2.0) & \\
\hline $40-59$ & $39(4 I .1)$ & $29(31.5)$ & \\
\hline $60-80$ & $40(42.1)$ & $52(56.5)$ & \\
\hline Mean age & $58.8 \pm 12.7$ & $54.8 \pm 13.5$ & \\
\hline \multicolumn{2}{|l|}{ Gender, number (\%) } & & 0.41 \\
\hline Male & $48(50.5)$ & $52(56.5)$ & \\
\hline Female & $47(49.5)$ & $40(43.5)$ & \\
\hline \multicolumn{2}{|l|}{ ASA class, number (\%) } & & 0.59 \\
\hline Classes I and II & $25(26.3)$ & $23(25.0)$ & \\
\hline Class III & $67(70.5)$ & $68(73.9)$ & \\
\hline Class IV & $3(3.2)$ & I (I.I) & \\
\hline \multicolumn{2}{|c|}{ Education level, number (\%) } & & 0.59 \\
\hline Primary school and none & $44(46.3)$ & $48(52.2)$ & \\
\hline High school & $34(35.8)$ & $32(34.8)$ & \\
\hline College and above & $17(17.9)$ & $12(13.0)$ & \\
\hline
\end{tabular}

Notes: Categorical variables were estimated by the chi-square test. $P<0.05$ indicates statistical significance.

Abbreviations: CICARE, Connect, Introduce, Communicate, Ask, Respond and Exit program; n, number; ASA, American Society of Anesthesiologists. the mean scales 4.3 (SD: 0.6) and 4.4 (SD: 0.6) in the "after CICARE" group were significantly greater than those of the "before CICARE" group (mean: 3.9, SD: 0.5; mean: 4.0, SD: $0.6 ; P<0.001$ and $P<0.001$, respectively; mean change difference $=0.4$ and 0.4 , respectively). As for the communication skills regarding initial explanation on the use of PCA, follow-up questions and ask-and-response of APS team members during ward visits, the mean scores for Q3, Q4, Q6 and Q7 for the APS team in group "after CICARE" were significantly greater than those in group "before CICARE" (all $P<0.001$ ) (all mean change differences $>0.3$ ). As expected, CICARE effectively improved the communication skills of the APS team members. These results demonstrate that communication skills can be improved through training. However, the results of Q5 revealed the efficacy of CICARE training for the ward nurses as only a statistical significance $(P<0.001)$, without any significant clinical difference (mean change difference $=0.2$ ). In Q8 concerning instrument proficiency, the mean change difference $(0.2)$ did not meet the criteria of minimal clinically important difference $(>0.3)$, although a statistically significant difference was noted between the two survey groups $(P<0.001)$ (Table 4).

\section{Additional assessments}

In the first 24 hours after surgery, $16.30 \%$ (15 patients) of the patients in group "after CICARE" rated their pain at rest as $\geq 4$, which was close to that $(18.95 \%, 18$ patients $)$ of the group "before CICARE" $(P=0.64)$. Similarly, there was no difference in the rates of inadequately treated pain at rest in the second 24 hours after surgery between the two survey groups $(7.37 \%$ vs $6.52 \%)(P=0.82)$. Furthermore, no differences were found in the dosage of morphine, the delivery/ demand ratios and the rates of side effects in the "first" or "second" 24 hours after surgery between groups (Table 5). Taken together, CICARE did not affect actual pain scores, drug consumption, the delivery/demand ratios and the rates of side effects in IV-PCA patients.

\section{Discussion}

In this study, implementing CICARE into SOP for APS represented a nonpharmacological intervention focusing on effective communication and standardization (greater adherence to protocol). ${ }^{15,17,33}$ Using questionnaires (patientreported outcomes), the impact of nonpharmacological interventions in APS was investigated in postoperative IV-PCA patients after major surgery. ${ }^{17}$ Primary and secondary outcomes revealed that CICARE incorporated into SOP effectively increased scores of PGI-Improvement in pain, 
Table 4 Responses to questionnaires between survey groups, namely, "before" and "after" CICARE, in postoperative patients receiving PCA

\begin{tabular}{|c|c|c|c|c|c|}
\hline \multicolumn{2}{|c|}{ Questions (Q) ${ }^{\mathbf{a}}$} & \multirow{2}{*}{$\begin{array}{l}\text { Before CICARE, } \\
\text { mean } \pm \text { SD } \\
3.9 \pm 0.5\end{array}$} & \multirow{2}{*}{$\begin{array}{l}\text { After CICARE, } \\
\text { mean } \pm \text { SD } \\
4.3 \pm 0.6\end{array}$} & \multirow{2}{*}{$\begin{array}{l}\text { P-value } \\
<0.001\end{array}$} & \multirow{2}{*}{$\begin{array}{l}\begin{array}{l}\text { Mean change } \\
\text { difference }^{b}\end{array} \\
0.4\end{array}$} \\
\hline QI & Was PCA information easily accessible for you to obtain? & & & & \\
\hline Q2 & Was a PCA device readily available for your pain management? & $4.0 \pm 0.6$ & $4.4 \pm 0.6$ & $<0.001$ & 0.4 \\
\hline Q3 & Was the initial explanation on the use of PCA clear? & $4.0 \pm 0.6$ & $4.4 \pm 0.6$ & $<0.001$ & 0.4 \\
\hline Q4 & Was the APS team's communication comprehensible during ward visits? & $4.1 \pm 0.5$ & $4.5 \pm 0.5$ & $<0.001$ & 0.4 \\
\hline Q5 & If there were problems with PCA, did the ward nurse promptly respond? & $4.2 \pm 0.6$ & $4.4 \pm 0.6$ & $<0.001$ & 0.2 \\
\hline Q6 & If there were problems with the PCA, did the APS team promptly respond? & 4. $1 \pm 0.6$ & $4.5 \pm 0.5$ & $<0.001$ & 0.4 \\
\hline Q7 & $\begin{array}{l}\text { If you experienced side effects of PCA, were you satisfied with the APS } \\
\text { team's response? }\end{array}$ & $3.9 \pm 0.5$ & $4.3 \pm 0.5$ & $<0.001$ & 0.4 \\
\hline Q8 & Was the APS team proficient when operating the PCA device? & $4.2 \pm 0.5$ & $4.4 \pm 0.5$ & $<0.001$ & 0.2 \\
\hline Q9 & $\begin{array}{l}\text { Was using PCA effective in reducing pain? (patient global impression } \\
\text { of improvement in pain) }\end{array}$ & $4.0 \pm 0.6$ & $4.4 \pm 0.6$ & $<0.001$ & 0.4 \\
\hline Q10 & Were you satisfied with the APS team services? & $3.8 \pm 0.5$ & $4.3 \pm 0.6$ & $<0.001$ & 0.5 \\
\hline
\end{tabular}

Notes: aSurvey responses were assessed by a 5 -point Likert scale for each question, with I representing extremely poor and 5 indicating excellent. ${ }^{b}$ Mean change difference: the difference between mean scores of "before CICARE" and "after CICARE" groups. Continuous variables were estimated by the Student's $t$-test. $P<0.05$ indicates statistical significance.

Abbreviations: APS, acute pain service; CICARE, Connect, Introduce, Communicate, Ask, Respond and Exit program; PCA, patient-controlled analgesia.

patient satisfaction and communication skills of APS team members, as well as accessibility and availability of PCA, in the "after CICARE" group compared to those in the "before CICARE" group. These findings substantiate that communication and adherence to protocol can be improved through training and SOP.

The results of Q9 and Q10 showed that implementing CICARE into SOP for ward visits effectively enhanced PGI-Improvement in pain and patient satisfaction on APS. Interestingly, no significant differences between "before" and "after CICARE" groups was found in the rates of inadequately treated pain at rest - a quality indicator of postoperative pain control. Different cutoff points for acute postoperative pain management lead to different study results. In this study, the cutoff point for inadequately treated pain at rest was defined as NRS $\geq 4$, which has been demonstrated to be optimal by Gerbershagen et al. ${ }^{23}$ Furthermore, there were no significant differences in the dosage of morphine and the delivery/ demand ratios between groups. These seemingly paradoxical responses were similar to previous findings from PAIN OUT, ${ }^{34}$ a European Union-funded acute pain registry and research project. They conclude that satisfaction with postoperative pain treatment is strongly linked to the impression of improvement and appropriateness of care; however, it is less associated with the patients' actual pain. ${ }^{34}$ Postoperative pain is affected by multiple factors, including anxiety, age, surgical types, anesthetic techniques ${ }^{35}$ and psychological factors, which effective communication influences. ${ }^{36,37}$

Table 5 Morphine dosage, delivery/demand ratio, pain severity and rates of side effects in patients receiving patient-controlled analgesia in the "first" and "second" 24 hours after surgery between the survey groups "before" and "after" CICARE

\begin{tabular}{|c|c|c|c|c|c|c|c|}
\hline \multirow[t]{2}{*}{ Variables } & \multirow[t]{2}{*}{ Response } & \multicolumn{2}{|l|}{ First 24 hours } & \multirow[t]{2}{*}{$P$-value } & \multicolumn{2}{|l|}{ Second 24 hours } & \multirow[t]{2}{*}{$P$-value } \\
\hline & & $\begin{array}{l}\text { Before CICARE } \\
(n=95)\end{array}$ & $\begin{array}{l}\text { After CICARE } \\
(n=92)\end{array}$ & & $\begin{array}{l}\text { Before CICARE } \\
(n=95)\end{array}$ & $\begin{array}{l}\text { After CICARE } \\
(n=92)\end{array}$ & \\
\hline Morphine, mg & - & $34.68 \pm 18.66$ & $30.37 \pm 15.42$ & 0.09 & $21.09 \pm 11.38$ & $18.34 \pm 10.57$ & 0.09 \\
\hline Delivery/demand ratio & - & $0.66 \pm 0.22$ & $0.65 \pm 0.20$ & 0.80 & $0.68 \pm 0.22$ & $0.68 \pm 0.18$ & 0.95 \\
\hline \multirow[t]{2}{*}{ Pain at rest, NRS score: $0-10$} & $\geq 4$ & 18 & 15 & 0.64 & 7 & 6 & 0.82 \\
\hline & $<4$ & 77 & 77 & & 88 & 86 & \\
\hline \multirow[t]{2}{*}{ Itching } & Yes & 11 & 8 & 0.43 & 6 & 2 & 0.16 \\
\hline & No & 84 & 84 & & 89 & 90 & \\
\hline \multirow[t]{2}{*}{ Dizziness } & Yes & 22 & 22 & 0.90 & 10 & 12 & 0.29 \\
\hline & No & 73 & 70 & & 85 & 80 & \\
\hline \multirow[t]{2}{*}{ Nausea and/or vomiting } & Yes & 21 & 15 & 0.41 & 5 & 9 & 0.24 \\
\hline & No & 74 & 77 & & 90 & 83 & \\
\hline
\end{tabular}

Notes: Categorical variables were estimated by the chi-square test. $P<0.05$ indicates statistical significance.

Abbreviations: CICARE, Connect, Introduce, Communicate, Ask, Respond and Exit program; NRS, numeric rating scale. 
The paradoxical responses in this study indicate that improvement of pain management in clinical pain studies should be assessed concurrently by two measurements, including NRSs and patient-reported outcomes. ${ }^{2,38}$

Reducing the side effects of IV-PCA is an alternative approach to improve patient satisfaction for pain control. ${ }^{11}$ Similarly, there were no differences in the rates of side effects of IV-PCA in the "first" and "second" 24 hours after surgery between groups. Nonetheless, patient satisfaction for IV-PCA management significantly increased after CICARE training. According to the improvements in Q3, Q4, Q6 and Q7, improved communication behaviors of APS team members could have contributed to the results. When treating patients, technical knowledge and skills of physicians and other staff members are essential; however, effective communication can be equally as important. ${ }^{10,11,33}$ The results were consistent with the recommendations of Meissner et $\mathrm{al}^{2}$ that better professional training of the pain team, greater adherence to protocol and good physician-patient communication are key priorities for improving postoperative pain management.

Q5 was set up as a control question compared to Q6. Despite "CICARE" being implemented throughout the entire Medical Center staff, patients were more satisfied with the APS team members than with ward nurses when experiencing PCA problems. It may be attributed to the fact that APS team members were more experienced and had more specialized training in pain management than ward nurses. In this study, APS nurses documented patients' pain scores regularly, whereas ward nurses were not required to assess and document patient's pain reports regularly. Documented pain scores have been shown to ensure effective communications between health care professionals and patients. Nurses who do not document pain scores may ignore the importance of pain management. ${ }^{6-8,39,40}$ Moreover, the APS team receives regular reinforcement of CICARE in monthly staff meetings. ${ }^{28}$ The findings support Cole's proposal that all medical providers, including ward nurses, should work closely with pain management specialists and take more time to know the best pain strategies for all patients under all circumstances. ${ }^{28,41}$

As for instrument proficiency, no significant clinical difference was noted in Q8. Previous studies have shown that technical quality and proficiency are more difficult for patients to judge even after the service has been performed. ${ }^{33}$ This may explain why patients reported no clinical difference on Q8. Nonetheless, patients' confidence in professionals is important in pain management. ${ }^{42,43}$ Further work on promoting patients' confidence on instrument proficiency is needed.
There were some limitations in this study. First, the current study was a nonrandomized, controlled before-after study for evaluating the effectiveness of the intervention. The before group receiving the IV-PCA alone without CICARE acted as a control group (no-intervention arm). ${ }^{13-15,44}$ The potential limitations of this design include lack of randomization and the presence of temporal confounders. However, the analysis revealed that there were no significant differences in the baseline characteristics and performances of participants between the before group (control group) and the after group. ${ }^{45}$ In addition, random withholding of a quality improvement intervention will not be allowed generally because of ethical considerations. Second, those who responded to the questionnaires are not representative of the others who did not. The effective response rate of questionnaires in this study was $>50 \%$, which is regarded as an adequate response rate. ${ }^{46}$ Third, this study included a small number of research participants. Fourth, this research was conducted in a single institution. Further large-sized and multiple-hospital studies are needed to validate our findings.

\section{Conclusion}

This study confirms the aspect that communication skills are learnable and improvable when implementing a quality improvement program into SOP. ${ }^{12,17}$ Nonpharmacological interventions conducted through implementing CICARE into SOP for APS can effectively enhance pharmacological treatment for acute pain management and optimize patient satisfaction with IV-PCA. ${ }^{2-6}$ Patient feedback from questionnaires can be informative for organizing educational service programs and improving APS performance. However, investigation into the impact of proper communication skills on individual subunits of hospital staffs is warranted in further studies.

\section{List of abbreviations}

APS, acute pain service; CICARE, Connect, Introduce, Communicate, Ask, Respond and Exit; IRB, institutional review board; ICU, intensive care unit; I-CVI, item-level content validity index; IV-PCA, intravenous patient-controlled analgesia; NRS, numeric rating scale; PCA, patient-controlled analgesia; PGI-Improvement, patient global impression of improvement; PSQ, patient satisfaction questionnaire; Q, question; SD, standard deviation; SOP, standard operating procedure; UCLA, University of California - Los Angeles.

\section{Acknowledgments}

We appreciate the helpful remarks from Chung-His Hsing, Professor, Department of Anesthesiology, Chi Mei Medical 
Center, Tainan, Taiwan, Republic of China. We thank Dr ChunHao Chen and nurse Yu Li Cheng for their help in the study.

\section{Author contributions}

J-Y Chen, C-C Chuang and W-J Wu have designed the original questionnaire. C-C Chuang was a major contributor in writing the manuscript. C-C Lee, L-K Wang, and B-S Lin were involved in the study design and acquisition of data. $\mathrm{C}-\mathrm{H}$ Ho performed the statistical analysis. All authors have been involved in critical study concepts and design, acquisition of data, revisions and editing of the manuscript and have approved the final draft.

\section{Disclosure}

The authors report no conflicts of interest in this work.

\section{References}

1. Gan TJ, Habib AS, Miller TE, White W, Apfelbaum JL. Incidence, patient satisfaction, and perceptions of post-surgical pain: results from a US national survey. Curr Med Res Opin. 2014;30(1):149-160.

2. Meissner W, Coluzzi F, Fletcher D, et al. Improving the management of post-operative acute pain: priorities for change. Curr Med Res Opin. 2015;31(11):2131-2143.

3. Patak LS, Tait AR, Mirafzali L, Morris M, Dasgupta S, Brummett CM. Patient perspectives of patient-controlled analgesia (PCA) and methods for improving pain control and patient satisfaction. Reg Anesth Pain Med. 2013;38(4):326-333.

4. Jamison RN, Taft K, O'Hara JP, Ferrante FM. Psychosocial and pharmacologic predictors of satisfaction with intravenous patient-controlled analgesia. Anesth Analg. 1993;77(1):121-125.

5. Lin CT, Albertson GA, Schilling LM, et al. Is patients' perception of time spent with the physician a determinant of ambulatory patient satisfaction? Arch Intern Med. 2001;161(11):1437-1442.

6. Momeni M, Crucitti M, De Kock M. Patient-controlled analgesia in the management of postoperative pain. Drugs. 2006;66(18):2321-2337.

7. Rawal N. 10 years of acute pain services - achievements and challenges. Reg Anesth Pain Med. 1999;24(1):68-73.

8. Ready LB, Oden R, ChadwickHS, et al. Development of an anesthesiologybased postoperative pain management service. Anesthesiology. 1988; 68(1):100-106.

9. Leonard M, Graham S, Bonacum D. The human factor: the critical importance of effective teamwork and communication in providing safe care. Qual Saf Health Care. 2004;13(suppl 1):i85-i90.

10. Travaline JM, Ruchinskas R, D'Alonzo GE Jr. Patient-physician communication: why and how. J Am Osteopath Assoc. 2005;105(1):13-18.

11. Hocking G, Weightman WM, Smith C, Gibbs NM, Sherrard K. Measuring the quality of anaesthesia from a patient's perspective: development, validation, and implementation of a short questionnaire. BrJ Anaesth. 2013;111(6):979-989.

12. Makoul G. MSJAMA. Communication skills education in medical school and beyond. JAMA. 2003;289(1):93.

13. Wen T, Huang B, Mosley V, Afsar-Manesh N. Promoting patientcentred care through trainee feedback: assessing residents' C-I-CARE (ARC) program. BMJ Qual Saf. 2012;21(3):225-233.

14. Rubin AD. Behavioral economics and Stanford Health Care's C-ICARE patient experience. In: Phillips RA, editor. America's Healthcare Transformation: Strategies and Innovations. New Brunswick, New Jersey, USA: Rutgers University Press; 2016:336-344.

15. Joseph A, Michelli P. Prescription for Excellence. Vol 1. 1 ed. New York: McGraw-Hill; 2011.
16. Dugdale DC, Epstein R, Pantilat SZ. Time and the patient-physician relationship. J Gen Intern Med. 1999;14(suppl 1):S34-S40.

17. Li JT. The quality of caring. Mayo Clin Proc. 2006;81(3):294-296.

18. Schoenfelder T, Klewer J, Kugler J. Determinants of patient satisfaction: a study among 39 hospitals in an in-patient setting in Germany. Int J Qual Health Care. 2011;23(5):503-509.

19. Alaloul F, Williams K, Myers J, Jones KD, Logsdon MC. Impact of a script-based communication intervention on patient satisfaction with pain management. Pain Manag Nurs. 2015;16(3):321-327.

20. Henriksen KM, Heller N, Finucane AM, Oxenham D. Is the patient satisfaction questionnaire an acceptable tool for use in a hospice inpatient setting? A pilot study. BMC Palliat Care. 2014;13:27.

21. Breivik H, Borchgrevink PC, Allen SM, et al. Assessment of pain. Br J Anaesth. 2008;101(1):17-24.

22. Lin YT, Lan KM, Wang LK, et al. Incidence, risk factors, and phenomenological characteristics of postoperative delirium in patients receiving intravenous patient-controlled analgesia: a prospective cohort study. Neuropsychiatr Dis Treat. 2016;12:3205-3212.

23. Gerbershagen HJ, Rothaug J, Kalkman CJ, Meissner W. Determination of moderate-to-severe postoperative pain on the numeric rating scale: a cut-off point analysis applying four different methods. Br J Anaesth. 2011;107(4):619-626.

24. Capuzzo M, Gilli G, Paparella L, et al. Factors predictive of patient satisfaction with anesthesia. Anesth Analg. 2007;105(2):435-442.

25. van Campen C, Sixma H, Friele RD, Kerssens JJ, Peters L. Quality of care and patient satisfaction: a review of measuring instruments. Med Care Res Rev. 1995;52(1):109-133.

26. Thayaparan AJ, Mahdi E. The patient satisfaction questionnaire short form (PSQ-18) as an adaptable, reliable, and validated tool for use in various settings. Med Educ Online. 2013;18:21747.

27. Polit DF, Beck CT, Owen SV. Is the CVI an acceptable indicator of content validity? Appraisal and recommendations. Res Nurs Health. 2007;30(4):459-467.

28. Karlsten R, Strom K, Gunningberg L. Improving assessment of postoperative pain in surgical wards by education and training. Qual Saf Health Care. 2005;14(5):332-335.

29. Lader MH. Handbook of Psychiatry. Vol 2. London: Cambridge University Press; 1983.

30. Howard ZD, Noble VE, Marill KA, et al. Bedside ultrasound maximizes patient satisfaction. J Emerg Med. 2014;46(1):46-53.

31. Sullivan GM, Artino AR Jr. Analyzing and interpreting data from Likert-type scales. J Grad Med Educ. 2013;5(4):541-542.

32. Revicki D, Hays RD, Cella D, Sloan J. Recommended methods for determining responsiveness and minimally important differences for patient-reported outcomes. J Clin Epidemiol. 2008;61(2):102-109.

33. Bendapudi NM, Berry LL, Frey KA, Parish JT, Rayburn WL. Patients' perspectives on ideal physician behaviors. Mayo Clin Proc. 2006; 81(3):338-344

34. Schwenkglenks M, Gerbershagen HJ, Taylor RS, et al. Correlates of satisfaction with pain treatment in the acute postoperative period: results from the international PAIN OUT registry. Pain. 2014;155(7): 1401-1411.

35. Ip HY, Abrishami A, Peng PW, Wong J, Chung F. Predictors of postoperative pain and analgesic consumption: a qualitative systematic review. Anesthesiology. 2009;111(3):657-677.

36. Perry F, Parker RK, White PF, Clifford PA. Role of psychological factors in postoperative pain control and recovery with patient-controlled analgesia. Clin J Pain. 1994;10(1):57-63; discussion 82-85.

37. Taenzer P, Melzack R, Jeans ME. Influence of psychological factors on postoperative pain, mood and analgesic requirements. Pain. 1986; 24(3):331-342.

38. Rothman M, Vallow S, Damaraju CV, Hewitt DJ. Using the patient global assessment of the method of pain control to assess new analgesic modalities in clinical trials. Curr Med Res Opin. 2009;25(6): 1433-1443.

39. Beaumont K, Luettel D, Thomson R. Deterioration in hospital patients: early signs and appropriate actions. Nurs Stand. 2008;23(1):43-48. 
40. Ene KW, Nordberg G, Bergh I, Johansson FG, Sjostrom B. Postoperative pain management - the influence of surgical ward nurses. J Clin Nurs. 2008;17(15):2042-2050.

41. Cole BE. The state of pain management. FDA Consum. 2004; 38(2):40.

42. Purtilo RB, Haddad AM, Doherty RF. Health Professional and Patient Interaction. 8th ed. St. Louis, MO: Elsevier/Saunders; 2014.

43. Gonzalez-de Paz L, Kostov B, Lopez-Pina JA, Solans-Julian P, NavarroRubio MD, Siso-Almirall A. A Rasch analysis of patients' opinions of primary health care professionals' ethical behaviour with respect to communication issues. Fam Pract. 2014;32(2):237-243.
44. World Medical Association. World Medical Association Declaration of Helsinki. Ethical principles for medical research involving human subjects. Bull World Health Organ. 2001;79(4):373-374.

45. Grimshaw J, Campbell M, Eccles M, Steen N. Experimental and quasi-experimental designs for evaluating guideline implementation strategies. Fam Pract. 2000;17(suppl 1):S11-S16.

46. Bernard HR. Research Methods in Anthropology: Qualitative and Quantitative Approaches. London: Rowman \& Littlefield Publishers; 2011. 


\section{Supplementary material}

Table SI Standard operating procedures of CICARE for APS team members during postoperative visits

\begin{tabular}{ll}
\hline Component & Procedure \\
\hline Connect & Eye-to-eye contact and smile while properly addressing the patient and checking his/her conscious level. \\
Introduce & $\begin{array}{l}\text { Introduce ourselves as the APS team and our responsibilities; demonstrate the functions of the portable handheld pulse oximeter } \\
\left(\mathrm{SpO}_{2} \text { monitor); connect the patient's finger to the pulse oximeter. }\right.\end{array}$ \\
Communication & Explain the readings on the pulse monitor. Reinforce drug information and the operating procedures of the PCA device. \\
Ask & $\begin{array}{l}\text { Assess pain severity using the II-point NRS. Ask about side effects (itching, dizziness, nausea or vomiting) and whether the patient } \\
\text { has experienced any trouble when using the PCA device. }\end{array}$ \\
Respond & Respond to PCA questions and treat any side effects accordingly. \\
Exit & Exit courteously after reminding patients how to contact the APS team if encountering PCA problems and to make a follow-up visit.
\end{tabular}

Abbreviations: APS, acute pain service; CICARE, Connect, Introduce, Communicate, Ask, Respond and Exit program; $\mathrm{SpO}_{2}$, oxygen saturation of pulse oximetry; PCA, patient-controlled analgesia; NRS, numeric rating scale (NRS: 0-10, with 0 indicating no pain and 10 indicating the most pain imaginable).

\section{Publish your work in this journal}

Neuropsychiatric Disease and Treatment is an international, peerreviewed journal of clinical therapeutics and pharmacology focusing on concise rapid reporting of clinical or pre-clinical studies on a range of neuropsychiatric and neurological disorders. This journal is indexed on PubMed Central, the 'PsycINFO' database and CAS, and is the official journal of The International Neuropsychiatric Association (INA). The manuscript management system is completely online and includes a very quick and fair peer-review system, which is all easy to use. Visit http://www.dovepress.com/testimonials.php to read real quotes from published authors. 